\title{
Aging in Resilient Communities-An Alpine Case Study: The Senior Living Lab Experience
}

Susan Riva-Mossman*

Department of Cultural and Social Studies, Medical Anthropology Program, Creighton University, Omaha, United States

*Corresponding author: Susan Riva-Mossman, Department of Cultural and Social Studies, Medical Anthropology Program, Creighton University, Omaha, United States; E-mail: su.riva@bluewin.ch

Received date: August 06, 2018; Accepted date: August 29, 2018; Published date: September 10, 2018

Copyright: (2018 Riva-Mossman S. This is an open-access article distributed under the terms of the Creative Commons Attribution License, which permits unrestricted use, distribution, and reproduction in any medium, provided the original author and source are credited.

\begin{abstract}
The Senior Living Lab led by the University of Applied Sciences and Arts in Western Switzerland, provides an interesting case study that sheds insight into user centered approaches to innovation in community healthcare platforms addressing aging. The Senior Living Lab was also an example of nursing leadership, focusing on social innovation from a perspective of care. The participative nature of the qualitative research methods in the field, allowed seniors to have a voice in the co-creation process, generating social innovation solutions within an interdisciplinary research framework. Through focus groups, World Café meetings, as well as a film event on hopeful, healthy aging, senior participant's views were valued. One fundamental message emerged from the dialogical space: seniors don't want to be stigmatized by a growing form of discrimination referred to as ageism. Synergies reinforced Alpine governance and wellness through collaborative continuums with communal authorities and regional stakeholders, applying participative research methods.
\end{abstract}

Keywords: The Senior Living Lab; Innovation; Shared value; Healthy aging

\section{Introduction}

The Senior Living Lab's documentary film thematized life course narratives of older women $[1,2]$. The women's conversations within the Senior Living Lab, were a starting point that led to filmed interviews addressing the challenges inherent in aging while orienting the dialogue towards the capacity to overcome difficulties and the role of hope in learning lives $[3,4]$. The film establishes a relationship between hope and individual healthy aging strategies. The social learning process of older people, searching for solutions and imagining a hopeful future of healthy aging was documented through narratives and shared at an avant-première in the Sion, Switzerland library in conjunction with the Valais' Department of Culture. The film showing included a round-table discussion with local social and healthcare stakeholders.

Shared values in healthy aging emerged from the women's stories. The themes that were mentioned include, "transmission and the sharing of knowledge and life experiences, respect for personal rights and freedom to choose, and reciprocity understood as a healthy balance between giving and receiving, "The cycle of life that allows us to give back what we receive" [5]. These core components of healthy aging were voiced and shared along with messages of hope, giving testimony to the opportunities retirement has to offer in a community setting. The way we talk about aging as well as how we collectively perform aging, envisioning growing old in a hopeful societal narrative, were shown to be key components in the transformational process. The research suggests that relational networks can grow over time, generating social innovation in conjunction with aging. These networks include both online platforms connecting older people, as well as local organizations.
This exploratory study highlighted the epigenetic paradigm that stresses how environment and perceptions can influence DNA expression [6]. Lifelong learning and collective efficacy in relation to aging were investigated to better understand their relationship to successful aging. Qualitative methods were used to elicit stories of resilience in the face of societal challenges like aging and demographic change. Together participants crafted a learning organization platform adaptive to change. The Senior Living Lab contributed to the way older people socially construct healthy aging, underscoring individual strategies, professional practice, as well as policy implications. Through the narratives, a community dialogue emerged about healthy lifestyle choices and how they are understood to have an influence on epigenetic expressions. In conclusion, the investigative process showed how social and cultural determinants of health affect the well-being of older adults as well as the viability of their communities.

\section{A Relational Approach: Co-constructing Interfaces of Collaboration for Long-Term Healthy Aging}

In an attempt to build upon the Senior Living Lab experience, partnerships were formed to continue to invest in the region's social and healthcare networks that are dedicated to healthy aging in the Alps. Skills inspired from the narrative model in mediation and conflict resolution served to bring together different perspectives in a communal space dedicated to advancing the quality of life in the Alps [7]. This social mediation process continues to integrate new actors, adding to its generative force.

An important factor in the valley is the Bagnes Museum that organizes yearly conferences, bringing together researchers from the University of Applied Sciences and Arts in Western Switzerland with local stakeholders. The academic presentations, including local practitioners, offer a dialogical space where citizens and communal authorities discuss sustainable development, including the topic of healthy aging. These conferences facilitate the creation of collaborative 
interfaces. They also contribute by reinforcing a relational approach to regional development [8].

In a second case study that built upon the Senior Living Lab's exploratory research, several mountain communities that form the Commune de Bagnes, an Alpine region in Valais, Switzerland, participated in a World Café, in the spring of 2018. The World Café was organized in order to work with community officials to develop a coherent governance plan for seniors in the mountain villages and ski resort [9]. This initiative was done in collaboration with Pro Senectute Valais, a regional organization that works to improve the lives of senior citizens [10]. Their results informed local politicians that are responsible for providing services for an increasing number of older people in the mountain region. The participative approach that was used, served to reinforce the democratic nature of the governing process in Alpine communities.

Pro Senectute was mandated by the communal authorities of the Commune de Bagnes to do assessment in relation to their aging Alpine population several years before the World Café. The pilot project built on an initial needs assessment that had been previously shared and implemented. By organizing a World Café with the local citizens and stakeholders, the research process generated a communal approach integrating citizen's perspectives in an event. The information gathered at the World Café was presented to the Commune de Bagnes in the summer of 2018. The report's recommendations and conclusions will be used to orient the Alpine community's social and healthcare policy. This form of participatory governance is an example of social innovation. Pro Senectute has also begun a film project. This creative initiative is underway to prevent ageism by looking into perceptions of aging from a regional, cultural vantage point. Pro Senectute's applied research has reinforced regional knowledge in the domain of healthy aging.

This case study is part of a cantonal initiative to reinforce the $60+$ Platform created by the Valais Health Department and coordinated by Promotion Santé Valais [11]. The Commune of Bagnes offers an example of Alpine communities working together to provide services for their aging citizens. Though they are part of a larger cantonal framework, their unique Alpine environment requires their initiatives to take into consideration the Alpine context when finding solutions to questions like mobility and transportation. Access to healthcare can also be problematic in valleys that are far from hospitals. Recently a local healthcare clinic was built in Sembrancher, Valais to offer a healthcare center in proximity to the valley's population, facilitating access to care [12]. This overall collaborative endeavor aims to coconstruct a cultural approach while defining health policy specifically adapted to the needs of Alpine communities.

The District of Entremont, under the leadership of their prefect, has also recently funded, in conjunction with the Interreg Alpine Space Programme, a research project in relation to Alpine space and aging [13]. The research project will be carried out from 2018-2020. The best practices that will be identified, will serve to create a road map for healthy aging policy in Alpine regions. Communal authorities will participate in the investigative process, giving value to the importance of regional governance.

The growing interest in providing community resources for an aging population suggests that communities are more aware of the need to craft resilient communities faced with both ecological and demographic change. A better understanding of the ecological, biological, psychological, and sociological aspects of wellness has the potential of influencing a paradigm change in relation to the coconstruction of a culture of care. Intergenerativity is another conceptual framework that can reinforce collaboration between generations, working together in community learning organizations [14]. Reinforcing intergenerational relationships has proven to benefit aging people with dementia, as well as contributing to the quality of life of children. Effective interfaces between governmental authorities, national and regional organizations, as well as research initiatives, must be fostered to assure long-term social transformation processes.

Though these examples are local community examples, the Taos Institute is yet another model, reaching out to seniors with their Positive Aging Newsletter for over twenty years [15]. The Taos Institute demonstrates how older adults can create international virtual communities through online communities devoted to life-long learning. Mixed approaches to hopeful, healthy aging can combine both local governance and international learning organizations that bring people together with new technologies using internet, online learning programs, and options like Zoom (allowing face-to-face group exchanges) to communicate.

Still, not all older people have the skills to be able to use the new technologies to keep connected. The World Health Organization's continual effort to give value to elder voices, raising consciousness about ageism, is leading worldwide initiatives to take action in relation to eldercare [16]. Local communities are challenged to find new ways to implement policies that will reinforce citizen centered actions and resilient communities, crafting community platforms adaptive to ecological and social change in the Anthropocene epoch, "With the current mass extinction, then, we are leaving behind the Holocene period of the past ten thousand years and entering the Anthropocence, an era shaped primarily not by natural systems but by humans" [17].

\section{Socially and Economically Sustainable Alpine Wellness Engendering Flourishing Mountain Communities}

How can flourishing mountain communities be engendered, respecting their unique bioregion? What evidence-based, translational methods can elicit the coordination of political, economic, as well as social and healthcare networks capable of integrating new technological innovation, facilitating Alpine wellness? What conditions are necessary to enkindle collaborative and participatory processes, leading to community consensus building aimed to meet citizencentered needs? How can academic leadership co-construct shared value models with communal authorities, ensuring the sustainable economic viability of peripheral regions in the Alps? Interdisciplinary teams, in collaboration with communal and cantonal authorities, are required to respond in an integral way to this increasingly urgent question. Vulnerable Alpine regions are under great pressure to craft new economic, social, and educational platforms able to adapt to major changes and paradigm shifts that are affecting their viability. There is increasing evidence that innovation in touristic Alpine regions needs to be developed through exploratory, translational research frameworks that engender resilient Alpine communities.

The complexity of the challenges facing Alpine communities requires a robust scientific inquiry that brings together the expertise of scientists as well as local stakeholders and political authorities, collaboratively developing a translational research framework (learning organization platform) that can configure networks of knowledge while facing rapid societal change. Proposing translational research that applies recent scientific findings allows knowledge gain to 
be applied in useful ways. Applied research can be understood to encompass models that allow for community intelligence to increase, enabling citizens, residents, and tourists to participate in jointventures, elaborating new forms of economic, social and technological innovation. Alpine Wellness focuses on communities above $1,500 \mathrm{~m}$. This case study includes Verbier, a ski resort, and the surrounding mountain communities in the Val de Bagnes.

This Alpine case study showcases the work of regional community partners, authorities as well as stakeholders, in an effort to imagine hopeful outcomes in conjunction with increasing longevity, quality of life, and economic opportunity. Interdisciplinary approaches accompany the region by implementing qualitative methods in a transformational process. The goal is to engender flourishing Alpine communities that can contribute to hopeful healthy aging by fostering resilient communities. Knowledge sharing platforms and activities can inform communities, allowing residents to participate in decisionmaking processes that are 'future forming' [18]. Smart Alpine Living is a way forward, modeling Smart City incentives and applying them in Alpine environments. The social construction of flourishing mountain communities requires a new paradigm that values relationships and transformative processes capable of initiating social and economic change while harvesting scientific knowledge.

Collaborative partnerships have been formed, setting out to create a translational research framework where connections can be made to reinforce the interface between research and practice. Methods incorporating various forms of narrative inquiry in conjunction with qualitative needs assessment and other data collection, with people and for people is the goal of the regional Alpine project aiming to put people-centered change management at the core of the inquiry process. The various actors work together, bridging Alpine communities with value networks able to adapt services to changing societal contexts [19].

Seeking to improve overall regional coordination, resulting in more efficient healthcare and service delivery systems, as well as the creation of economic growth in the Alps, requires well-conceived governance strategies. The governance vision can then be applied using the knowledge gained from organizations like Pro Senectute that have been funded to care for an aging population and communal authorities. Within the context of demographic change, new governance models are required to accelerate socio-economic change processes, "However, maintaining vital communities in the mountains, (a problem common to the entire Alpine Region) is today an essential condition for the conservation of the landscape in all its diversity, for the physical protection of the territory and for the safeguarding of all those values associated with the local culture and traditions" [20]. Maintaining viable communities is central for both ecological conservation and demographic balance.

Action research can elicit social change through interdisciplinary and translational approaches, while developing effective empirical, well-sustained models that can be shared and demonstrated in other Alpine community contexts. By developing collaborative networks, it is possible to explore an evidence-based translational research model where social innovation can be collaboratively implemented with the support of local authorities and regional stakeholders, in an Alpine learning organization dedicated to Smart Alpine Living.

Synergies between the different actors in the regional network are the foundation of this case study. Together local actors and stakeholders can work to co-construct a Smart Alpine Living paradigm enabling both residents and tourists to contribute in the informing process, engendering knowledge through new forms of consultation. This case study proposes a needs assessment approach using qualitative methods, including the World Café method, as well as Community Based Participatory Research to develop a theoretical model for Alpine governance [21,22]. By taking into consideration the data collected in relation to frailty and vulnerability in aging populations, a translational research model that has the potential of becoming a transposable framework for other Alpine regions can be co-constructed within the context of interdisciplinary and qualitative research approaches.

As demographic change is currently influencing the economic viability of Alpine regions, coherent policies that attract residents at the age of retirement can also be seen as avenues for future development. Imagining policies capable of attracting 'new highlanders', may be an innovative way to leverage this new form of immigration for rural development. These amenity migration factors take into consideration landscape and socio-cultural aspects, as well as lifestyle. Low taxes and quality transportation systems have been identified as major considerations for 'multifocal' living in the Swiss Alps [23]. A theoretical model integrating the 'mountain factor' in relation to intercommunal migration and its potential influence for generating flourishing mountain communities may contribute to increasing Alpine Wellness, avoiding forced migration when communities are no longer able to offer jobs and services [24]. The quality of life in Alpine ski resorts like Verbier attracts new residents searching for mountain cities that offer infrastructural and cultural amenities, as well as leisure activities like skiing and other mountain sports [25].

Swiss mountain communities are facing development challenges as recent national legislation (the Lex Weber and the LATT) have forced communal authorities to make radical changes in the application of laws pertaining to property rights and zoning that have affected the regional social and economic tissue. Not only has legislation changed, but also other challenges like demographic and ecological change are forcing mountain communities to envision a new era, seeking a new definition of progress. 'Lifescaping' becomes an important endeavor considering most people will live on the average, approximately thirty years longer [26]. As Alpine regions are facing rapid demographic and ecological change, mountain communities must be accompanied in order to craft adaptable social and healthcare networks to meet current and future needs.

Demographic change can be perceived as an opportunity, enabling economic actors to benefit from the growing "Silver Economy". In the same sense, ecological change can be a catalyst for envisioning new life ways, through the development and coordination of service offers and leisure activities. As citizen empowerment and health literacy become recognized European goals, transformation enablers must be identified, and their skills taught within larger learning organizations so to benefit from increasing user-generated health and care data when anticipating the challenges of care [27].

The current social and economic capital has become fragile, following the drastic changes in legislature governing land use as aforementioned. It is imperative that regional higher learning institutions accompany mountain people in Alpine villages, during this transitional phase, towards a renewed vision of sustainable Alpine Wellness. In this way, our international Alpine communities can transfer the knowledge of a holistic and integral lifestyle through their activities in conjunction with the many tourists seeking to improve their well-being during their vacations in Valais. A Glocal approach, (both global and local) seeks to cultivate a sustainable social, 
economic, as well as natural capital capable of maintaining the region's precious natural and human resources [28]. The development of regional practices and teaching methods, fostered by reinforcing collaboration with the local service providers and Alpine communities, is an integral part of creating an Alpine Learning Organization Platform [29]. An interdisciplinary approach allows each discipline to cross-pollinate the other during the co-creation process, where environmental leadership plays an important role, involving multilevel transformational approaches for sustainability $[28,29]$. The five aspects of Alpline Wellness interact with each other, with a cross-pollinating effect (Figure 1) [30].

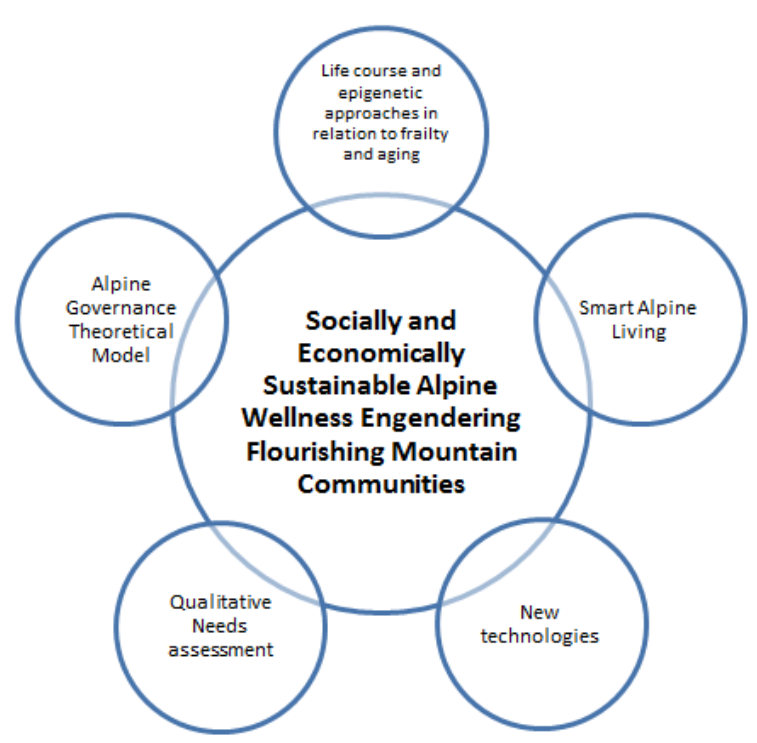

Figure 1: Socially and economically sustainable Alpine wellness engendering flourishing mountain communities

\section{A New Story of Alpine Aging}

We need a new story to bring us forward, translating social innovation to mountain communities. The use of narrative inquiry allows citizen-centered participatory methods to give voice to regional needs [31]. In Alpine regions there are competing interests and paradigms of development that must be reconciled. Other mountainous regions are dealing with similar challenges involving conflicting representations of nature and land use priorities that correspond with the representations of local inhabitants. "To understand the conflicts we need to see what people deeply care about in the first place. We need to know what identity shaping stories either large or small, they tell to make sense of their world and their place in it [32].

Focusing development on an integral approach that gives value to cultural heritage as well as the natural environment can engender more sustainable and flourishing Alpine communities. The Yale Forum of Religion and Ecology has been dedicated to addressing the Anthropocene Epoch by co-writing a new cosmology [33]. Inspired by the work of Thomas Berry, they are writing a new story that enables all world citizens to enter into a new relationship with their natural environment, by identifying with a cosmology story that integrates both science and religion. As human beings are storied creatures, we need a new story to enter into a transformational process that will allow us to find new ways of going forward in balance with our natural habitat [34]. Using narrative inquiry to better understand what the Alpine residents truly care about is one way to elicit social transformation processes from a position of relational responsibility [35]. This case study is an example of the challenging work that must be done [36]. Imaging and dreaming a hopeful future into the form of action plans can be facilitated with the use of Appreciative Inquiry to initiate the transformational process [37].

A culture of care that gives value to Alpine caretakers can be fostered with innovative action and research methods. A culture valuing care supports caretakers that care for the land, the animals, the buildings, as well as the people and tourists in the region. When seeking sustainable and integral development, it is necessary to invite participants into a new dialogue about how to shape the future of affiliated Alpine regions. This future forming approach elicits a local conversation, integrating new practices and shared values to reach regional goals. Governance and policy in relation to aging will benefit from an integral approach to Alpine Wellness. Integral ecology and Bronfenbrenner's Ecological Approach are foundational theoretical models to be integrated [38].

Generating a coherent vision of the network of services currently existing is essential when working to reinforce Alpine space. Preserving the natural environment has become a political priority. However, little research has been conducted pertaining to the social capital of the mountain people, taking into consideration their unique skills and culture. The growing international community in the District of Entremont offers a field of anthropological study encompassing the 4 Valley ski area with ski lifts that assure the liaisons. Interdisciplinary approaches linking ecological considerations that includes care, can be gathered together via an Alpine wellness learning platform, valuing regional knowledge and practices $[39,40]$.

An interdisciplinary approach serves to accompany a mountain community in their sustainable development process, co-constructing life styles in which Alpine communities can envision hopeful futures. Shared value economic principles applied to healthcare serve the greater community, guiding the emerging economic framework by giving value to preventive actions and building a culture of health [41]. Established practices in relation to care, a central uniting principle and theoretical back-drop, can serve to foster a new integral vision based upon a 'Culture of Care [42,43].

What actions can be taken locally that integrate the social and cultural determinant of health? [44]. Cultural and historical influences play a part in generating healthy aging. To ground regional research culturally and historically, it is important to include symbolic elements like the Great Saint-Bernard Hospice with its ancient tradition of hospitality as well as its unique ongoing relationship with the Alpine environment. The Hospice is geographically close to the Commune de Bagnes and is an important cultural heritage for the entire region. The hospice's example can be an important historical and cultural symbol, linking the past with the future. By giving value to cultural rootedness, communities can find their way into the future in a more meaningful way. The hospice's prior as well as Vervier's parish priest have participated in the consultation process, offering the church's resources to reinforce regional social capital and wellness from a rooted, cultural perspective.

The hospice's cultural role can help to guide the philosophical vision by offering a symbolic landmark and the example of a religious community that marks an important passage in time and space, 
transmitting traditional values and practices in a unique bioregion. Alpine Wellness places an important emphasis on the spiritual dimension of tourism that is attracting more and more people to mountain regions [45]. The increase in pilgrimages where people are walking from Canterbury to Rome on the Via Francigena trail has increased, offering a promising alternative to winter sport activities in the region. The Via Francigena Trail is considered a Major Cultural Route by the Council of Europe. It provides a recognized activity in relation to alternative wellness offers for the Great Saint Bernard Hospice and adjoining villages and ski resorts.

\section{Conclusion}

In conclusion, this case study shows how different research initiatives can be coordinated through new forms of Alpine governance to reinforce Smart Alpine Living, Alpine wellness, and hopeful healthy aging in Alpine communities. When funding runs out for research projects like the Senior Living Lab, it is important to foster continuity by linking research initiatives within regional policy frameworks to promote healthy aging long-term. These synergies can work to sustain the economic, social and healthcare networks. There appears to be a relationship between the ability of governing authorities to assure economic viability and quality of life for citizens.

The growing difference between life expectancy in European countries has been shown to correspond to economic factors that differ between countries as well as within countries. Many less economically developed European countries are seeing their life expectancy decrease, just as the poor in wealthy European countries are losing years in comparison to more wealthy citizens [46]. These trends encourage us to take action. Though new technologies bring global information and knowledge to remote areas, it is not enough to have access to online communities to sustain hopeful healthy aging. Local authorities must work to assure quality citizen-centered services. This can be done by enacting participative governance that can generate long-term Alpine Wellness as shown in this case study.

Co-constructing viable Alpine communities where aging populations can benefit from social and healthcare services can assure increased longevity and quality of life throughout the life course. It is necessary to support peripheral regions dedicated to reinforcing their social and healthcare networks so that Alpine residents will have an equal chance at hopeful healthy aging. The research process is strengthened by building partnerships and fostering synergies that in turn generate collaborative practices through applied research. Alpine wellness and healthy aging are related to governance strategies capable of responding to citizen's needs. This Alpine case study underscores the importance of long-term engagement and leadership from community authorities capable of working in collaborative interfaces with organizations and institutions, applying qualitative action research methods. Together, through collaborative partnerships, this case study suggests that it is possible to co-construct hopeful healthy aging strategies in the Alps.

\section{References}

1. Lab SL (2015) Senior Living Lab Lausanne: HES-S0.

2. Riva-Mossman S, Kampe T, Cohen C, Verloo H (2016) The Senior Living Lab: an example of nursing leadership. Clin Interv Aging 11: 255-263.

3. Riva-Mossman S, Verloo H (2017) Explorative healthy aging approaches fostering social innovation: thematizing life course narratives of older adult women participating in a documentary film. Qual Res Med Health 1: 18 .
4. Angeli L, Carrino S, Abou OK, Riva-Mossman S, Mugellini E (2016) Senior Living Lab: An Ecological Approach to Foster Social Innovation in an Aging Society. Future Internet 8: 50.

5. Riva-Mossman S, Verloo H (2017) Explorative healthy aging approaches fostering social innovation: thematizing life course narratives of older adult women participating in a documentary film. Qual Res Med Health 1: 14-22.

6. Lock M, Pálsson G (2016) In: Can science resolve the nature/nurture debate? John Wiley \& Sons, Cambridge, UK.

7. Cobb SB (2013) In: Speaking of violence: the politics and poetics of narrative dynamics in conflict resolution. Oxford University Press, Oxford, New York.

8. Gergen Kenneth J (2009) In: Relational being: beyond self and community. Oxford University Press, Oxford, New York.

9. Brown J, David I (2005) In: The World Café: shaping our futures through conversations that matter. (1st edn) Berrett-Koehler Publishers San Francisco, CA, USA.

10. Pro Senectute Valais

11. The Platform $60+$.

12. Medidranse.

13. Espace Alpin.

14. Whitehouse PJ, George D (2008) In: The myth of Alzheimer's: what you aren't being told about today's most dreaded diagnosis. (1st edn) St. Martin's Press, New York, USA.

15. Taos Institute Positive Aging Newsletter.

16. World Health Organization on ageing and life-course.

17. Swimme BT, Tucker ME (2014) In: Journey of the Universe. Yale University Press, New Haven \& London.

18. Gergen KJ (2014) From mirroring to world making: research as future forming. J Theory Soc Behav 45: 287-310.

19. Aida ME, Haselmayer S, Rasmussen JH (2010) In: Connected Cities: Your 256 Billion Euro Dividend: How Innovation in Services and Mobility Contributes to the Sustainability of Our Cities: A Handbook Royal College of Art, London, UK.

20. Cantini MG, Geitner C, Haida C, Fedirin M, Tallino C, et al. (2016) Balancing Economic Development and Environmental Conservation for a New Governance in Alpine Areas. J Sustainability 8: 802.

21. Brown J, David I (2005) In: The World Café: shaping our futures through conversations that matter. (1st edn) Berrett-Koehler Publishers San Francisco, CA, USA.

22. Coughlin SS, Smith SA, Fernández ME (2017) In: Handbook of community-based participatory research. Oxford University Press, New York, USA.

23. Olivier B, Kanitscheider S (2012) New Immigration Into the European Alps: Emerging Research Issues. Int Mount Soc 32: 235-241.

24. Camenisch M, Debarbieux B (2011) Inter-communal migrations in Switzerland: a "mountain factor". J Alpine Res 99: 6-15.

25. https://w2.vatican.va/content/dam/francesco/pdf/encyclicals/documents/ papa-francesco_20150524_enciclica-laudato-si_en.pdf mountain sports.

26. Carstensen, L (2011) In: A long bright future: happiness, health, and financial security in an age of increased longevity. Public Affairs, New York, USA.

27. https://ec.europa.eu/digital-single-market/en/blueprint-digitaltransformation-health-and-care-ageing-society

28. Coleman C (1998) Social Capital in the Creation of Human Capital. Am J Sociol 94: S95-S120.

29. Senge P (2011) The Dance of Change: The Challenges of Sustaining Momentum in Learning Organizations. Nicholas Brealey Publishing, London, UK.

30. Ramus C, Oppengaard K (2007) Integrating Compliance-based and Commitment-based approaches in Corporate Sustainability Management. 
Citation: $\quad$ Riva-Mossman S (2018) Aging in Resilient Communities-An Alpine Case Study: The Senior Living Lab Experience. J Aging Sci 6: 193. doi:10.4172/2329-8847.1000193

Page 6 of 6

31. Clandinin DJ (2013) In: Engaging in narrative inquiry. Developing qualitative inquiry. Left Coast Press, Inc, Walnut Creek, California, USA.

32. Farrell J (2015) The battle for Yellowstone: morality and the sacred roots of environmental conflict. Princeton studies in cultural sociology. Princeton University Press, Princeton, USA pp. 9.

33. Yale Forum of Religion and Ecology.

34. Berry T (2015) In: The Dream of the Earth. Counterpoint Press, California, United States.

35. McNamee S, Kenneth JG (1998) In: Relational responsibility: resources for sustainable dialogue. SAGE Publications, California, United States.

36. Berry T (2000) In: The Great Work: Our Way intothe Future. Bell Tower, New York, USA.

37. Cooperrider DL, Whitney D, Stavros JM (2008) In: Appreciative Inquiry Handbook: For Leaders of Change. (2nd edn.) Berrett-Koehler Publishers, Ohio, USA.

38. Bronfrenbrenner U (1979) In: The Ecology of Human Development, Harvard University Press, USA.

39. Wenger E (2014) In: Learning in landscapes of practice: boundaries, identity, and knowledge ability in practice-based learning. Routledge, London, UK.
40. Wenger E, White N, Smith J (2009) In: Digital Habitats: Stewarding Technology for Communities. Portland, Orlando, USA.

41. Porter M (2009) "Creating Shared Value in Health Care" Building a Culture of Health: A New Imperative for Business, Harvard Business School and Robert Wood Johnson Foundation, Boston, USA.

42. The Encyclical Letter, Laudato Si', of the Holy Father Francis, On Care For Our Common Home.

43. Durant AF, McDermott S, Kinney G, Triner T (2015) Caring Science: Transforming the Ethic of Caring-Healing Practice, Environment, and a culture within an Integrated Care Delivary System 19: e136-142.

44. Donkin A, Goldblatt P, Allen J (2017) Global actionon the social determinantsof health. BMJ Glob Health 1: e000603

45. Voigt Cornelia, Christof Pforr (2014) In: Wellness tourism: a destination perspective. Routledge advances in tourism. Routledge, London, UK.

46. Dérens Jean-Arnault, Geslin, Laurent (2018) Boulversement Démographique En Europe. In: Dérens JA, Geslin L (eds.) Le Monde Diplomatique.
This article was originally published in a special issue, entitled: "Aging Challenges in a Digital World", Edited by Dr. Fereshteh Barei, Paris Dauphine university, Paris, France. 